\title{
Demography and age structures of coral reef damselfishes in the tropical eastern Pacific Ocean
}

\author{
M. G. Meekan ${ }^{1, *}$, J. L. Ackerman' ${ }^{2}$, G. M. Wellington ${ }^{3}$ \\ ${ }^{1}$ Australian Institute of Marine Science, PO Box 264, Dampier, Western Australia 6713, Australia \\ ${ }^{2}$ Department of Marine Biology, James Cook University, Queensland 4810, Australia \\ ${ }^{3}$ Department of Biology and Biochemistry, University of Houston, Texas 77204-5513, USA
}

\begin{abstract}
Few studies have examined spatial variation in the demography or age structures of coral reef fishes. We analysed sectioned sagittal otoliths to describe the age structures, growth and mortality of 5 species of Stegastes damselfishes. These were sampled at localities near the centre (Panamá) and at the northern (Baja California) and southern (Galápagos) edges of the eastern Pacific tropical reef environment. Widespread damselfishes were sampled at Panamá and Baja (S. flavilatus) and at Panamá and the Galápagos (S. acapulcoensis). The 3 remaining species were endemic to the Galápagos Archipelago (S. arcifrons, S. leucorus beebei) and Baja California (S. rectifraenum). We found that populations of widespread species in the Galápagos and Baja grew to larger adult sizes, had relatively long life spans and lower rates of mortality once asymptotic mean sizes were attained than populations of the same species in Panamá. These characteristics of long adult life spans and low mortality rates were shared by endemic species in the Galápagos and Baja. Our analysis revealed strong year classes that corresponded to the timing of El Niño-Southern Oscillation events in the age structures of both a widespread and an endemic species in the Galápagos Archipelago.
\end{abstract}

KEY WORDS: Otolith $\cdot$ Demography $\cdot$ Coral reef fish $\cdot$ Age $\cdot$ Growth $\cdot$ Adult

\section{INTRODUCTION}

In contrast to temperate regions, where the demography of fish populations has been a central element of fisheries research for most of this century, studies of the demography of coral reef fishes are a relatively recent development. The growth of this field has largely been driven by 2 factors: first, the realisation that the otoliths of tropical reef fishes can be easily interpreted to provide reliable and accurate estimates of age (Fowler 1990, 1995) and second, the need for basic information on the life history parameters of reef species in order to manage exploitation by expanding human populations in tropical regions (Russ 1991, Munro 1996).

Prior to the last decade, coral reef fishes were generally assumed to be short-lived and fast-growing, with relatively high rates of mortality (Sale 1980). Since this

*E-mail:m.meekan@aims.gov.au time, studies using otolith-based techniques have shown that this is often not the case. Average life spans of 30 to $40 \mathrm{yr}$ have been reported for acanthurids (Choat \& Axe 1996) and some lutjanids (Newman et al. 1996a,b), while life spans of labroid fishes can range from 5 to 20 yr (Choat et al. 1996). Even small reef fishes such as pomacentrids appear to be capable of attaining ages of more than $20 \mathrm{yr}$. As a result of these long life spans, populations of many species are dominated by older individuals and there is an accumulation of numerous age classes within a narrow adult size range (Choat \& Axe 1996, Craig et al. 1997). Due to variable rates of growth among individuals, strong year classes of adults within a population are often invisible in length-frequency distributions (Russ et al. 1996). These characteristics have important consequences for management, since species exhibiting long life spans and low rates of natural mortality have relatively low sustainable yields to fisheries (Russ 1991, Ferreira \& Russ 1994, 1995). 
Despite the fragmented distributions of coral reefs, there have been few attempts to examine spatial variation in life history traits of reef fishes. To date, the majority of otolith studies of coral reef fishes have focused on a very limited range of latitudes on the Great Barrier Reef in the western Pacific. For a restricted subset of species that are the primary targets of reef fisheries, estimates of growth, mortality and longevity are available from a number of localities (e.g. Munro \& Williams 1985). However, this information provides little insight into spatial patterns, since demographic parameters are confounded by fishing mortality and differences in effort by fishermen among localities. Furthermore, the results of many of these studies are based on length-frequency analyses rather than aging by otoliths. These techniques require a strong correlation between size and age of individuals, so that cohorts of fish can be followed through time within populations. Given the life history traits of reef fishes revealed by aging work, such analyses are unlikely to produce accurate estimates of demographic parameters (Russ et al. 1996).

Here, we examine spatial variation in the demography and age structures of coral reef fishes in the eastern tropical Pacific. Damselfishes were selected for the study since they share many of the life history traits such as sex reversal and potentially long life spans that are typical of larger, mobile species of reef fish such as serranids, lethrinids, scarids and labrids. Unlike these larger species, which may comprise a relatively rare component of fish assemblages, damselfishes can be extremely abundant and are easily collected. Damselfishes are not a target of fisheries in the region, thus patterns in their demography can be examined without the confounding effects of variation in fishing effort among localities.

Our study examined the demography and age-structures of 2 widespread damselfishes, Stegastes flavilatus and $S$. acapulcoensis, and 3 insular endemic damselfishes, S. arcifrons, $S$. leucorus beebei and S. rectifraenum. The widespread damselfishes were sampled near the centre of their range at the Perlas Islands, which lie in the Gulf of Panamá, close to the mainland coast, and at 2 localities on the edge of the species range (the Galápagos Archipelago and Baja California). Damselfishes endemic to the Galápagos and Baja were also sampled in order to determine if the patterns seen in the widespread damselfishes were typical of other species in these localities.

\section{METHODS}

Study species and localities. Both Stegastes arcifrons and $S$. leucorus beebei are confined to the Galápagos Archipelago (Ecuador), Isla del Malpelo
(Colombia) and Isla del Coco (Costa Rica). S. rectifraenum occurs along the coast of Baja California and Gulf of California. In contrast, $S$. acapulcoensis and $S$. flavilatus occur from the southern end of Baja along the entire mainland Pacific coast to Perú (Allen \& Robertson 1994). S. acapulcoensis is also found in the Galápagos Archipelago.

In January 1995, we collected a total of 132 adult Stegastes acapulcoensis, 309 S. arcifrons and 521 S. leucorus beebei by spearing from 9 sites on 8 islands (Floreana, Isabela, Fernandina, Marchena, Genovesa, Bartolomé, Rabida and Seymour) in the Galápagos Archipelago (Fig. 1). In May 1996, we collected 240 S. rectifraenum and $45 \mathrm{~S}$. flavilatus from 3 sites near the lower end of the Baja Peninsula in the Gulf of California. A total of 356 S. acapulcoensis and 108 S. flavilatus were collected in June 1996 at 4 sites in the Perlas Islands, which lie close to the mainland coast in the Gulf of Panamá.

Standard lengths of fishes were measured immediately following capture and their sagittae were removed. These were stored dry and later weighed to the nearest $0.1 \mathrm{mg}$ in the laboratory. A sub-sample of 155 Stegastes arcifrons, 214 S. leucorus beebei and 146 $S$. rectifraenum otoliths were selected for analysis in proportion to the abundance of these species in catches at each site. Catches within each site were divided into $5 \mathrm{~mm}$ standard length classes and the individuals for the sub-samples selected in proportion to the abundance of each size class. The otoliths of these sub-sampled fishes and from all individuals of
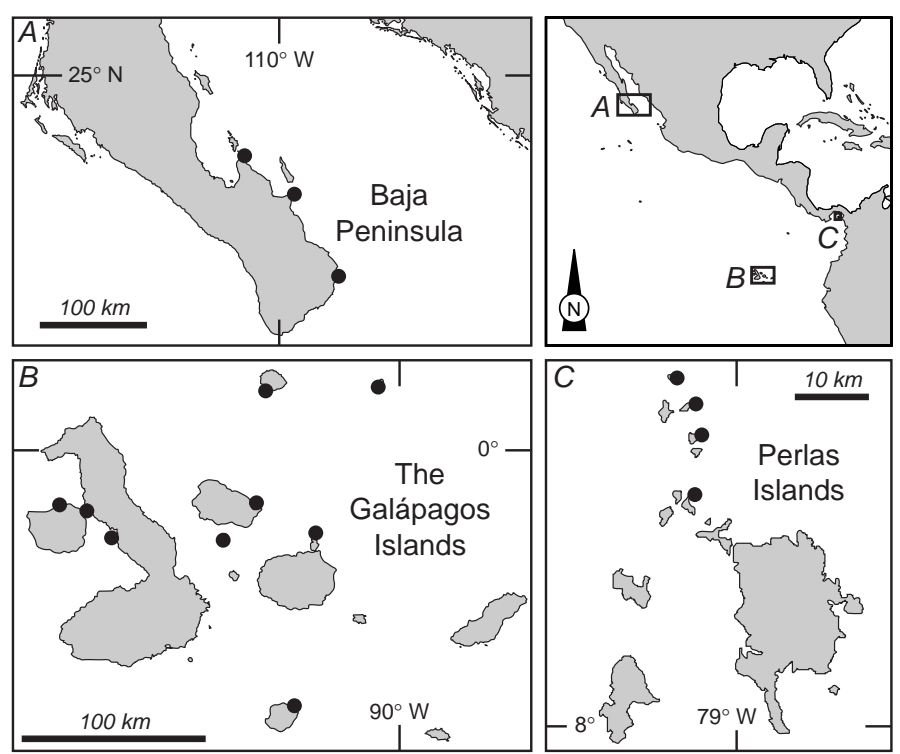

Fig. 1. Localities sampled during the study. (A) Baja California; (B) The Galápagos Archipelago; (C) The Perlas Islands, Gulf of Panamá. Sampling sites are indicated $(\bullet)$ 
the remaining species were embedded in resin blocks, sectioned transversely, and the section then mounted on a glass slide. The section was polished using lapping film and examined under a microscope using transmitted light at $60 \times$ magnification. A more detailed description of these methods is given in Meekan et al. (1999).

Three separate counts of opaque zones were made by the same reader (M.G.M.) along a consistent axis within each otolith. When age estimates varied, counts were repeated twice more. If estimates still did not converge, those otoliths were removed from the analysis. On average, $18 \%( \pm 9 \mathrm{SD})$ of otoliths of each species were rejected on this basis.

The annual deposition of growth increments in the otoliths of Stegastes arcifrons, S. acapulcoensis and $S$. leucorus beebei has been validated by the presence of checks generated by El Niño-Southern Oscillation (ENSO) events (Meekan et al. 1999). Although comparable checks did not exist in $S$. flavilatus and $S$. rectifraenum, the internal structure of their otoliths closely resembled that of congeneric species (see Figs. 1 \& 2 in Meekan et al. 1999). We thus assumed that increments were also formed on an annual basis in these species.

Statistical analysis. The relationship between otolith weight and increment number was examined using regression analysis. These analyses were then used to provide predicted ages for those individuals not included in sub-samples. Regressions were also used to generate ages for those fishes for which a precise estimate could not be obtained from otoliths or whose otoliths were lost or damaged during age analysis. Reliable estimates of otolith weight were not available for a small number (4 to 5) of individuals of each species. These fishes were excluded from further analysis.

Von Bertalanffy growth functions (VBGF) provided the best fit to size-at-age data according to the parameter estimates of the Schnute (1981) growth function. As collections occurred at times when there were few newly settled fishes, the intercepts of curves were constrained to the approximate sizes at settlement $(11 \mathrm{~mm}$, Wellington \& Robertson unpubl. data). Subsequently, the von Bertalanffy parameter $t_{0}$ (theoretical age when length is zero) was constrained to -0.1 for all species at all locations, approximating values attained by constraining length intercepts. Growth curves and confidence intervals about curve parameters were calculated using Excel and subprograms of the Statistical Package for the Social Sciences. Approximate 95 \% ellipsoidal confidence regions around the parameter estimates $k$ (coefficient of growth) and $L_{\infty}$ (mean asymptotic length) were used to compare the growth functions among species and populations (Draper \& Smith 1966, Kimura 1980).
Mortality rates were calculated using log-linear regression analyses of age-frequency data sets. Year classes to the left of the age-frequency mode were excluded from the analysis, since sampling targeted only larger fishes (Pauly 1984, Ferreira \& Russ 1992). Because of the remote nature of some of the localities, our study could only be based on single collections of adults. Analysis of these data sets, using log-linear models, required that levels of recruitment to populations varied randomly about a mean value (i.e. there was no long-term trend in recruitment patterns). Our data sets appeared to conform to this assumption; however, the weighting of exceptional year classes on regression lines were also of concern. In order to examine such effects the analysis was repeated, firstly with the complete data set and then after the removal of large year classes. Slopes of the regression lines were compared using analysis of covariance (ANCOVA; Zar 1984).

\section{RESULTS}

\section{Otolith weight versus age}

Generally, there were strong relationships between otolith weight and age of Stegastes damselfishes (Fig. 2). For all species, with the exception of S. flavilatus in Baja, the largest $\mathrm{r}^{2}$ values were obtained by calculating non-linear relationships between otolith weight and age.

\section{Longevity and age structure}

The small damselfishes sampled by our study were remarkably long-lived (Fig. 3). In the Galápagos Archipelago, some individuals in our collections of Stegastes acapulcoensis and $S$. arcifrons had attained ages of $>20 \mathrm{yr}$, while a few individuals of $S$. leucorus beebei were estimated to be $>15$ yr old. In Panamá, $S$. acapulcoensis did not attain ages as great as those recorded in the Galápagos, although a few individuals at this locality were found to be $>10 \mathrm{yr}$ old. S. flavilatus was also relatively short-lived in Panamá, with the oldest fish estimated to be only 4 yr of age, while in Baja a few individuals of this species attained ages of $>15 \mathrm{yr}$. The remaining species, $S$. rectifraenum, attained ages of up to 10 yr at Baja.

Age-frequency distributions of Stegastes damselfishes are shown for each locality in Fig. 3. Distributions of $S$. arcifrons, $S$. leucorus beebei and $S$. flavilatus did not include age estimates derived from regressions between otolith weight and age, as errors introduced by models tended to smooth age distributions, obscur- 


\section{Galápagos}

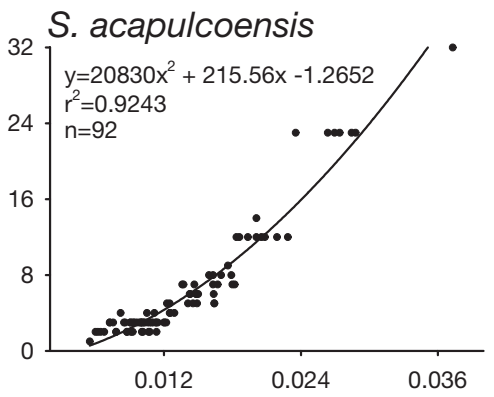

Panamá

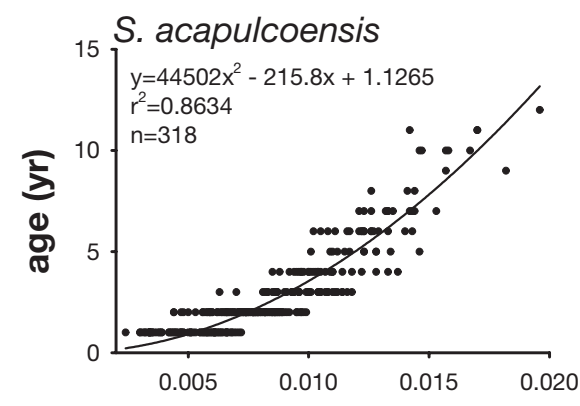

Baja

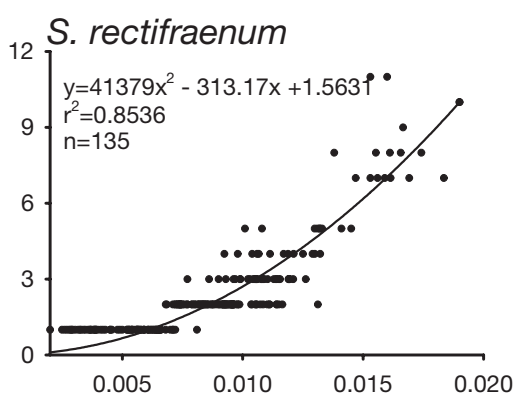

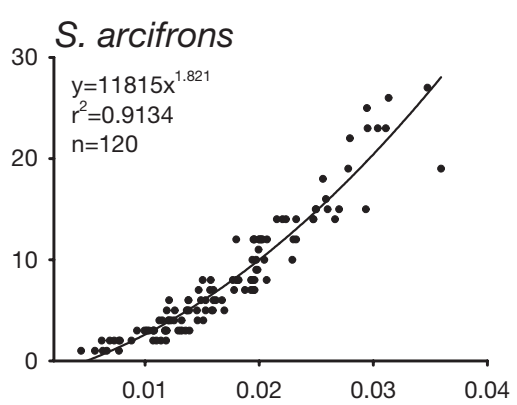

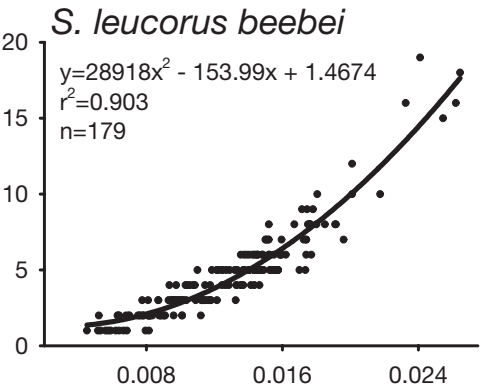

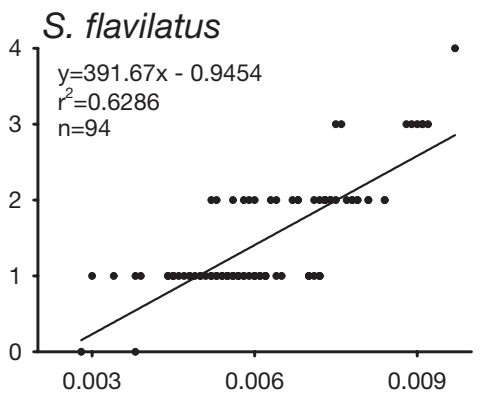

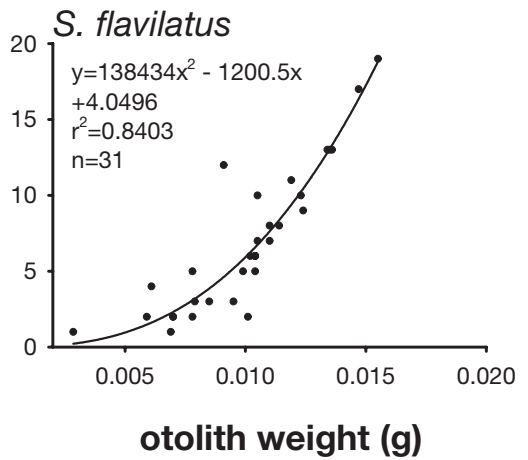

Fig. 2. Stegastes spp. Otolith weight versus age for damselfishes in 3 localities in the tropical eastern Pacific Ocean. Relationship fitted by regression analysis is shown on each plot. Formula and $\mathrm{r}^{2}$ calculated by the regression is given. $\mathrm{n}=$ sample size in figure

ing prominent year classes. Strong year classes of 8,12 and $23 \mathrm{yr}$ old fish were evident in the age distribution of $S$. acapulcoensis in the Galápagos (Fig. 3). The timing of these corresponded to years when large ENSO events occurred in the Archipelago. Strong year classes of 8 and $12 \mathrm{yr}$ old fish were also present in the distributions of $S$. arcifrons at this locality (Fig. 3). The age structures of both these species were very similar, although, in contrast to $S$. acapulcoensis, the age distribution of older $S$. arcifrons was composed of many year classes, suggesting that recruitment of this species was not as sporadic as that of $S$. acapulcoensis. There was no evidence of strong year classes corresponding to the timing of ENSO events in the age structure of $S$. leucorus beebei. Abundances declined sharply in older age classes, with only $3.5 \%$ of the fish sampled by our study attaining ages of $>10 \mathrm{yr}$.
In Panamá, the age distributions of Stegastes acapulcoensis and S. flavilatus did not display any evidence of strong year classes corresponding to oceanographic events such as ENSO (Fig. 3). Distributions of these species displayed a relatively smooth decline in abundances of older age classes. A similar pattern was also found in the age structure of $S$. rectifraenum in Baja. In contrast, the age structure of $S$. flavilatus in Baja was broadly distributed across many age classes.

With the exception of Stegastes flavilatus in Panamá and $S$. rectifraenum in Baja, the age distributions of all species initially increased and then declined, so that fish aged 2 to 3 yr were the most abundant year class in the population. This result was probably an artefact of the sampling technique, which targeted adult fishes. Age classes of 1 or 2 yr old fish that were dominated by juveniles where underrepresented in collections. 


\section{Growth}

In the Galápagos Archipelago, Stegastes acapulcoensis, $S$. arcifrons and $S$. leucorus beebei all grew at similar rates during their first year of benthic life, attaining an average standard length of $67 \mathrm{~mm}$, although adult size differed among these species (Table 1, Fig. 4). Fitting of VBGFs to age and size data sets gave mean asymptotic standard lengths (Francis 1995) of 119, 104 and $94 \mathrm{~mm}$ for $S$. acapulcoensis, $S$. arcifrons and $S$. leucorus beebei respectively. In Panamá, S. acapulcoensis and S. flavilatus both grew to average standard lengths of $76 \mathrm{~mm}$ during the first year, with the former species attaining a mean length of $111 \mathrm{~mm}$ while the latter species averaged $85 \mathrm{~mm}$ (Table 1). Mean asymptotic lengths of 107 and $97 \mathrm{~mm}$ were calculated for $S$. rectifraenum and for $S$. flavilatus respectively in the Baja Peninsula.

Comparisons of $95 \%$ confidence ellipses indicated that there were significant differences in the VBGFs that were fitted to data sets of Stegastes acapulcoensis from coastal and island populations (Fig. 5). Adult $S$. acapulcoensis in the Galápagos attained larger mean sizes and much greater maximum ages than those in Panamá (Fig. 6). Significant differences were also evident in insular and coastal populations of the other widespread damselfish, S. flavilatus. In Baja, this species attained larger average sizes and maximum ages that were approximately 5 times those of coastal populations in Panamá (Fig. 6).

\section{Mortality}

With the exception of the data set for Stegastes acapulcoensis in the Galápagos, we found that removal of large year classes had little effect on the outcomes of the log-linear analyses. For this species, the 23 yr old

Table 1. Stegastes spp. Summary of von Bertalanffy growth functions fitted to age-at-size data sets for damselfishes from 3 localities in the eastern Pacific. $\mathrm{n}=$ sample size $L_{\infty}=$ mean asymptotic standard length $(\mathrm{mm}) ; k=$ coefficient of growth

\begin{tabular}{|lrrrc|}
\hline Species & $\mathrm{n}$ & \multicolumn{1}{c|}{$L_{\infty}$} & $k$ & $\mathrm{r}^{2}$ \\
\hline Galápagos & & & & \\
$\quad$ S. acapulcoensis & 130 & 118.8 & 0.77 & 0.5076 \\
$\quad$ S. arcifrons & 301 & 103.8 & 0.75 & 0.6959 \\
$\quad$ S. leucorus beebei & 514 & 93.6 & 0.70 & 0.6582 \\
Panamá & & & & \\
$\quad$ S. acapulcoensis & 351 & 111.5 & 1.08 & 0.6124 \\
$\quad$ S. flavilatus & 98 & 84.7 & 1.95 & 0.2900 \\
Baja & & & & \\
$\quad$ S. flavilatus & 32 & 97.2 & 1.30 & 0.4421 \\
$\quad$ S. rectifraenum & 237 & 107.3 & 1.11 & 0.6321 \\
& & & & \\
\hline
\end{tabular}
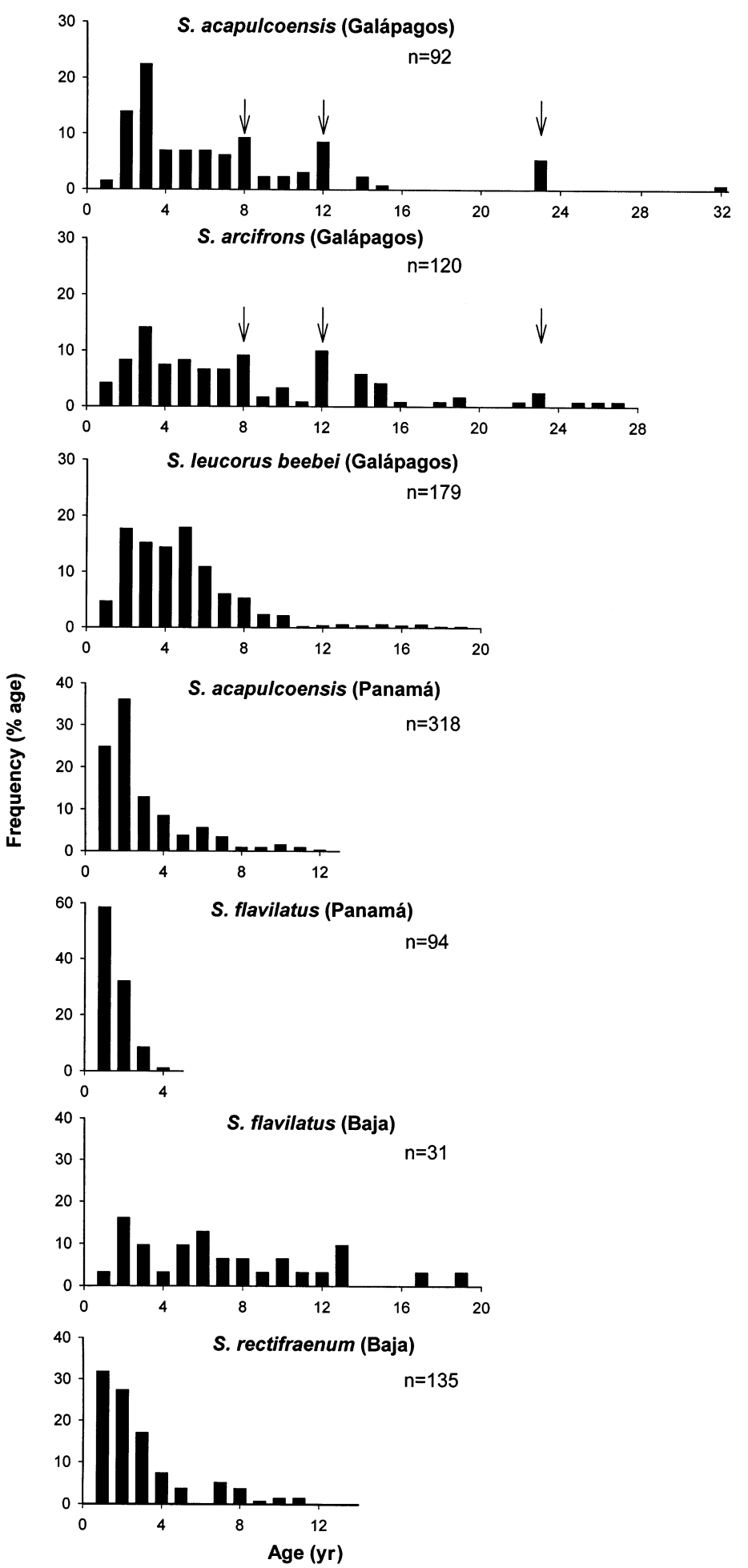

Fig. 3. Stegastes spp. Age-frequency distributions of damselfishes in 3 localities in the tropical eastern Pacific Ocean. Only age estimates derived from otoliths were used in the plots. Arrows show year classes that coincided with the timing of strong ENSO events in the Galápagos Archipelago during the 28 yr prior to our study. These events were identified from the data sets of sea-surface temperature anomalies 

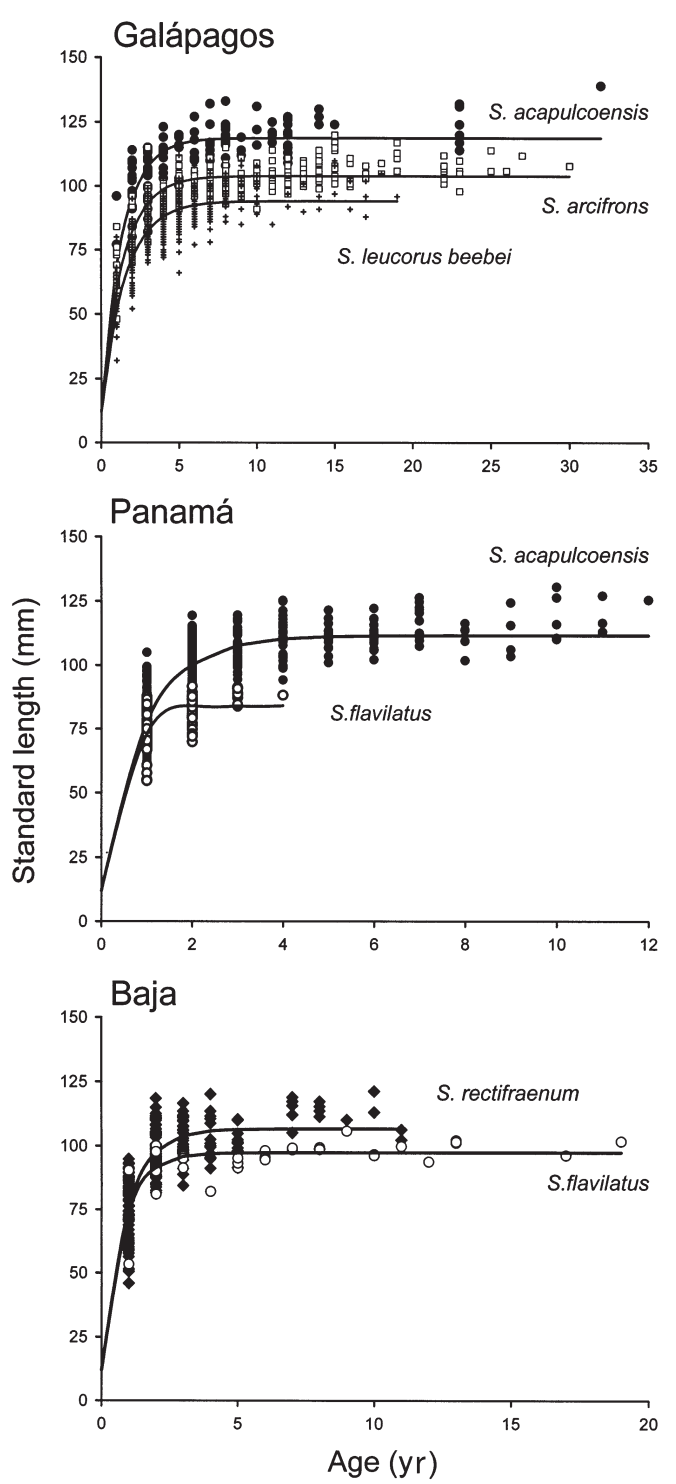

Fig. 4. Stegastes spp. Von Bertalanffy growth curves for Stegastes damselfishes from 3 localities in the tropical eastern Pacific Ocean. $t_{0}$ (theoretical age when length is zero) values were constrained to $-0.1 \mathrm{yr}$. Details of the analyses and curve statistics are given in Table 1

cohort was excluded in order to reduce the weighting effect it had on the analysis. The mortality patterns of Stegastes in each locality are shown in Fig. 7. In the Galápagos, both $S$. acapulcoensis and $S$. arcifrons had lower mortality rates than the smaller $S$. leucorus beebei (Table 2). Similarly, in Panamá, S. acapulcoensis also had a lower mortality rate than the smaller $S$. flavilatus (Table 2). However, in Baja this pattern was reversed, with the smallest species, S. flavilatus, displaying lower rates of mortality than $S$. rectifraenum (Table 2).

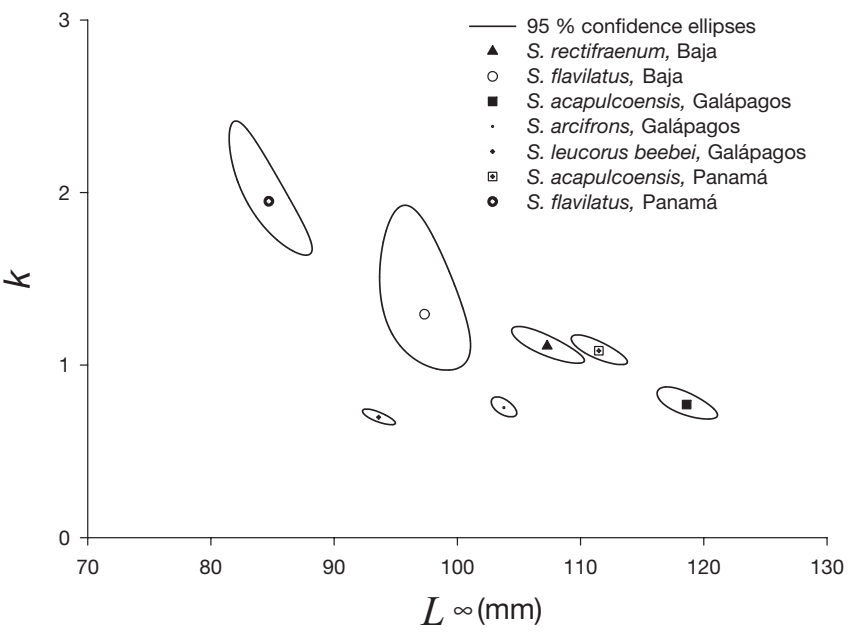

Fig. 5. Stegastes spp. Plots of approximate 95\% confidence regions around the parameter estimates $k$ (coefficient of growth) and $L_{\infty}$ (mean asymptotic standard length) of von

Bertalanffy growth curves for damselfishes at 3 localities

ANCOVAs demonstrated that mortality rates of Stegastes acapulcoensis were lower in the Galápagos than in Panamá, although this result should be treated with caution, given the potential for variable recruitment in older age classes (Table 2). Mortality of S. flavilatus was significantly lower in Baja than in Panamá (Fig. 7).

\section{DISCUSSION}

There were striking differences in the demography and age structures of widespread damselfishes between populations near the edge and at the centre of species ranges. In the Galápagos, adult Stegastes acapulcoensis attained a mean asymptotic length of $119 \mathrm{~mm}$ and a maximum age of 32 yr, while in Panamá, adults of this species grew to a mean length of $111 \mathrm{~mm}$ and maximum ages of only 12 yr. Similarly, adult $S$.

Table 2. Stegastes spp. Summary of ANCOVA comparisons of mortality rates of damselfishes in 3 localities in the eastern Pacific. $K=$ number of regression slopes used in comparison

\begin{tabular}{|lcccc|}
\hline & $K$ & $\mathrm{df}$ & $F$ & $\mathrm{p}$ \\
\hline $\begin{array}{l}\text { Galápagos } \\
\text { Panamá }\end{array}$ & 3 & 2,54 & 10.570 & 0.0001 \\
Baja & 2 & 1,11 & 26.135 & 0.0003 \\
$\begin{array}{l}\text { S. acapulcoensis (Galápagos) } \\
\text { S. acapulcoensis (Panamá) }\end{array}$ & 2 & 1,18 & 10.712 & 0.0042 \\
$\begin{array}{l}\text { S. flavilatus (Baja) } \\
\text { S. flavilatus (Panamá) }\end{array}$ & 2 & 1,22 & 9.7831 & 0.0053 \\
& & & & \\
\end{tabular}



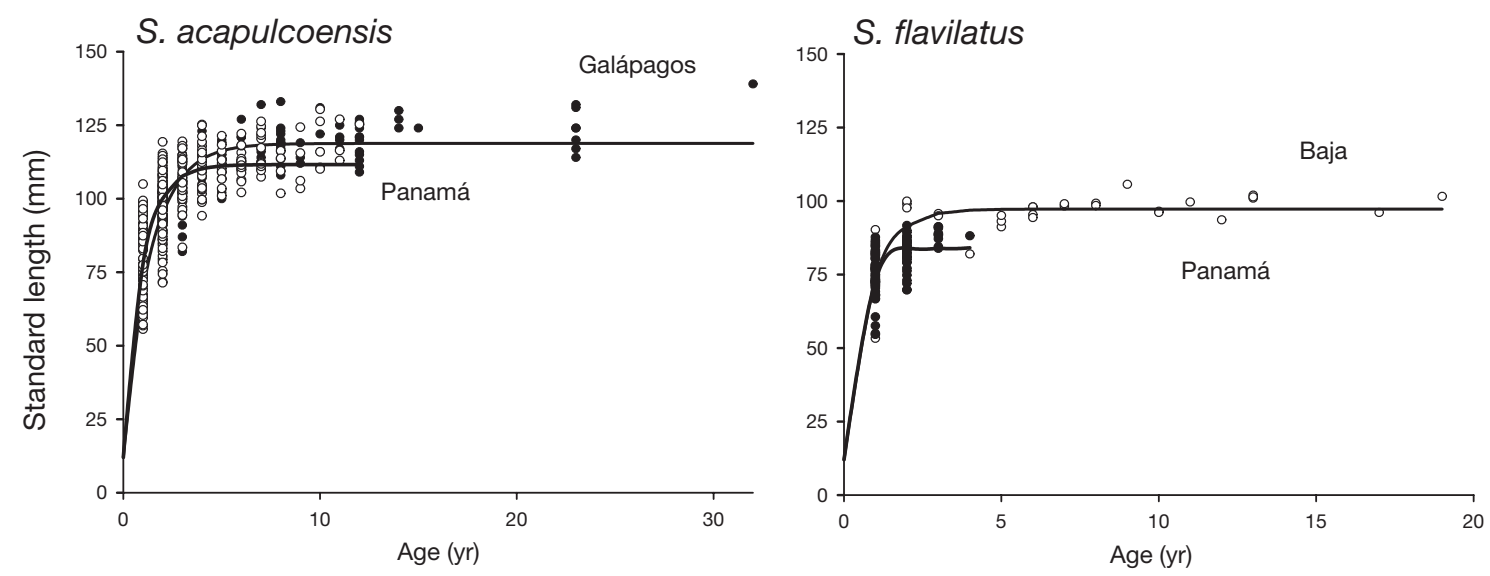

Fig. 6. Stegastes spp. Von Bertalanffy growth curves of widespread damselfishes sampled from the centre (Panamá) and at the edge (Galápagos, Baja) of their ranges. $t_{0}$ (theoretical age when length is zero) values were constrained to -0.1 yr. Details of the analyses and curve statistics are given in Table 1
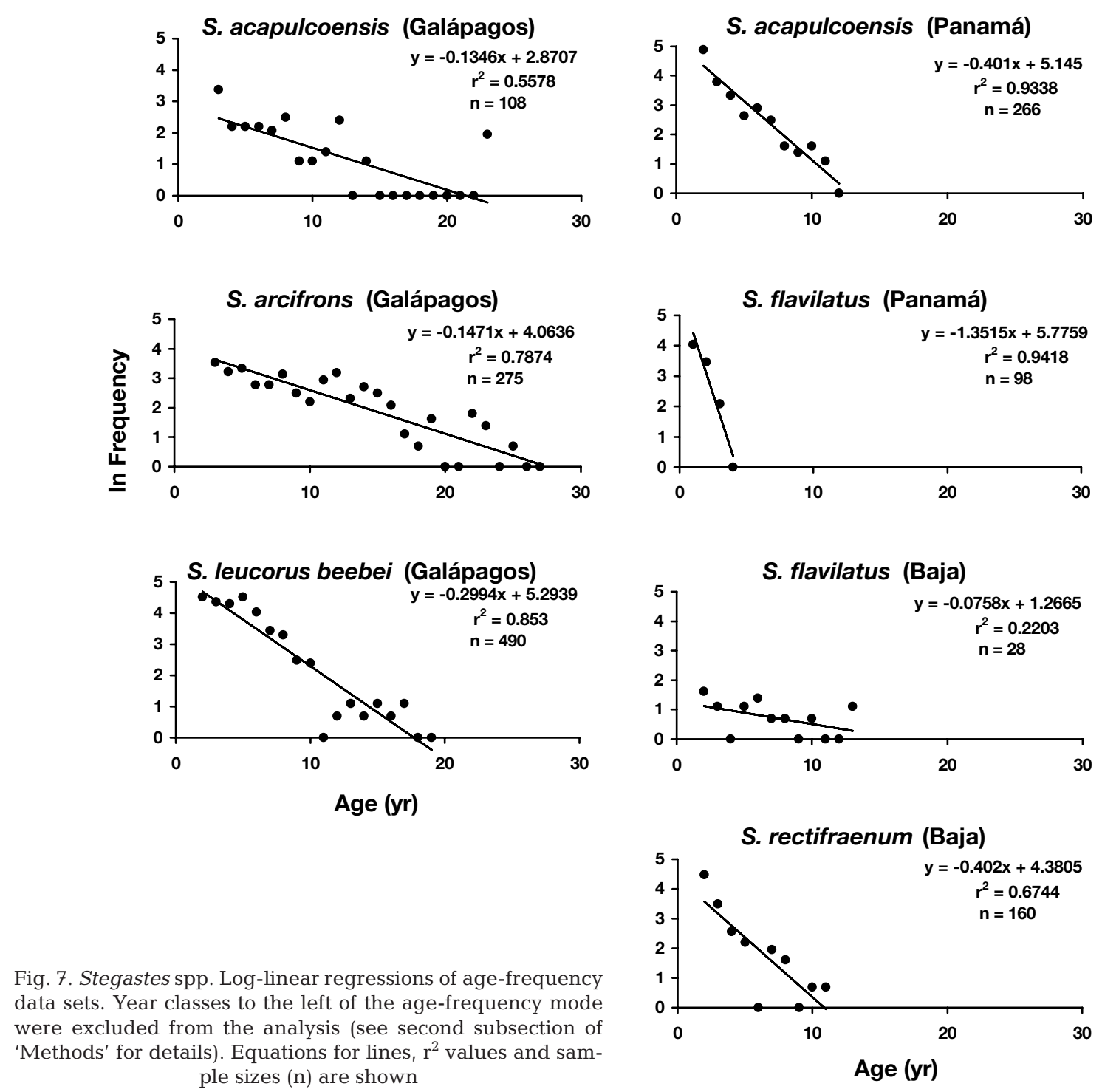
flavilatus grew to mean lengths of $97 \mathrm{~mm}$ and attained ages of up to $19 \mathrm{yr}$ in Baja, but only grew to $85 \mathrm{~mm}$ and maximum ages of $4 \mathrm{yr}$ in Panamá. These life history traits of low rates of mortality and relatively long life spans of widespread species in the Galápagos and Baja were consistent with those of congeneric species endemic to these localities.

For ectotherms such as fishes, it has long been recognised that adult size and life spans increase when there is a decline in average temperatures experienced by individuals during development (Atkinson 1994). In the Galápagos Archipelago, sea surface temperatures (SSTs) measured at Isla Santa Cruz range from monthly means of $21.5^{\circ} \mathrm{C}$ in August to $25.2^{\circ} \mathrm{C}$ in April, although water temperatures in the north of the Archipelago may attain temperatures of up to $30^{\circ} \mathrm{C}$ (Houvenaghel 1984). In contrast, SSTs in the Gulf of Panamá are somewhat warmer, with monthly averages ranging from 25.7 to $28.6^{\circ} \mathrm{C}$ (Wellington \& Dunbar 1995). While the effects of such differences in water temperature during development may account for the smaller size and shorter life spans of Stegastes in Panamá relative to those of populations in the Galápagos, this does not appear to be the case for populations in Baja. For at least half of the year, monthly averages of SST near our collection sites at the tip of the Peninsula overlap those occurring in Panamá, ranging from 21.5 to $29.3^{\circ} \mathrm{C}$ (data source: IRI/LDEO Climate Data Library, website address: http://ingrid.ldgo.columbia.edu). This lack of consistent differences in water temperature among localities implies that variability in the size and age structures of populations may be maintained by factors other than developmental conditions.

Variation in demography may also occur as a response to differing selective pressures among populations. When adult habitats are confined to a restricted area, they may present a relatively small target to reef fishes returning from the plankton. For this reason, the chances of successful recruitment of young fish in such localities may be less than that of situations where adult habitats occur over a wide geographic area. This in turn may promote strong selection for larger adult size and greater longevity in populations occupying restricted habitats in order to maximise reproductive output (Hutchings 1997). While such selective pressures might explain the relative sizes and ages of damselfishes in the small and isolated islands of the Galápagos, it is not consistent with the distributions of populations occurring along Baja Peninsula. Both Stegastes rectifraenum and $S$. flavilatus occupy very large areas, with the former species being found throughout the Gulf of California and along part of the western margin of the peninsula (Allen \& Robertson 1994). In Baja, as in Panamá, the wide range of adult populations would allow lar- vae the opportunity to settle long distances downstream of their natal reefs. Thus, it seems unlikely that such selective pressures can explain the relative sizes and age structures of damselfish populations among localities.

An alternative possibility is that variation in adult size might reflect differences in rates of predation among localities. Theoretical and experimental studies suggest that in fish populations where adults undergo high mortality, there is strong selection for maturation at young ages and greater reproductive effort, an outcome of which is relatively small adult size (Reznick et al. 1990, Fox \& Keast 1991, Hutchings 1997, Bertschy \& Fox 1999). Our observations were consistent with this idea; in Panamá where Stegastes damselfishes underwent higher rates of mortality and achieved lower maximum ages than populations in the Galápagos or Baja, we also found that adults attained smaller mean sizes. This phenomenon was not simply due to the removal of older (and thus larger) fishes from populations, as our analysis of growth curves showed that asymptotic lengths were attained very rapidly by damselfishes in all localities.

While our study supports the notion that there may be differences in rates of predation among localities, our estimates of mortality must be treated with caution. Ideally, mortality would be calculated by repeatedly sampling cohorts of fishes through time. As our work was based on single collections of adults, we estimated mortality using log-linear models (Pauly 1984). This approach requires that there is no long-term trend in levels of recruitment. Our data sets appeared to conform to this assumption, although we excluded some exceptional year classes from the analysis to remove their weighting effects on regression lines. We found that this made little difference to model outcomes, implying that the analyses were relatively robust.

Given the commonality of other life history traits, it seems possible that the variation in demographic patterns found in Stegastes damselfishes may be typical of other families of reef fishes. Some evidence that this is the case is provided by Craig et al. (1999), who examined the age and growth of the serranid Epinephelus labriformis in the Galápagos and at Puerto Vallarta on the mainland coast of Mexico. Similar to the patterns recorded in our study, these workers found that populations in the Galápagos attained greater mean asymptotic lengths and ages than those at the mainland location. If such attributes are indeed a general phenomenon, then this has important consequences for the management of reef fisheries in localities at the edge of species ranges, such as Galápagos and Baja. We found that populations of both widespread and endemic damselfishes at these localities tended to be dominated by older individuals. For example, in the Galápagos, 37 \% 
of the populations of $S$. acapulcoensis and $S$. leucorus beebei and $21 \%$ of the populations of $S$. arcifrons were $<4 \mathrm{yr}$ of age. In contrast, these young age classes made up $73 \%$ of the population of S. acapulcoensis and $99 \%$ of the population of $S$. flavilatus in Panamá. Additionally, studies in temperate environments demonstrate that recruitment patterns are likely to be more sporadic and variable near the edge of the species range (Myers 1991). These traits suggest that populations in the Galápagos and Baja may have slower rates of turnover than those in Panamá and, as a result, will be more vulnerable to fishing mortality than populations of the same species near the centre of the species' ranges.

Evidence of episodic recruitment was revealed in the age structures of some of our study species. Our analysis suggested that older individuals in populations of Stegastes acapulcoensis in the Galápagos were mostly derived from year classes that coincided with strong ENSO conditions. Direct observations following the 1982-1983 ENSO confirm enhanced recruitment of this species during these events (Grove 1984, Grove et al. 1986); however, the underlying causes of this pattern remain unclear. It has been suggested that strong ENSOs enhance the strength of the Panamá flow southward towards Galápagos, facilitating transport of larvae from reefs along the mainland coast of the eastern Pacific to the Galápagos (Glynn \& Wellington 1983). Evidence that such long-distance transport can occur is provided by the appearance in the archipelago of a number of species of reef fishes that, prior to the 1982-1983 ENSO, had never been recorded in this locality (Grove 1984, Merlen 1988). Long-distance transport would allow the large populations of $S$. acapulcoensis that exist on the mainland coasts to act as sources of larval supply for the Galápagos, possibly accounting for strong year classes. Alternatively, larvae could arrive routinely from mainland populations during normal seasonal cycles, but might require the environment created by strong ENSO events in order to survive to juvenile stages in benthic habitats. This seems unlikely, given that the age structure of $S$. acapulcoensis revealed many year classes of adult fish that had entered the population during years when ENSO events did not occur. A third possibility is that the ENSO phenomenon provides conditions that enhance the survival of planktonic larvae or juveniles produced by resident populations. Some evidence for this suggestion is provided by $S$. arcifrons. Similar to $S$. acapulcoensis, strong year classes of $S$. arcifrons that corresponded to the timing of ENSO events were evident in age distributions. Since this species is endemic to the archipelago, these year classes could not have resulted from long-distance transport, and thus may be due to enhanced survivorship of pelagic larvae and/or benthic juveniles.
There was little evidence of correlations between year class success and large-scale oceanographic events such as ENSO in the age structures of the remaining species. However, for populations of Stegastes flavilatus in Baja, this result must be treated with caution, since our analyses were based on relatively few individuals. When sample sizes are small, errors or uncertainty in age analysis will tend to smooth distributions and obscure prominent year classes. This source of error will be of increasing importance as the strength of the correlation between year class success and climatic or oceanographic phenomena declines. Furthermore, relatively short life spans such as those displayed by $S$. flavilatus in Panamá mean that any evidence of correlations will persist within the population for only a few years. Detection of strong year classes will thus require large sample sizes to be removed from the population at frequent intervals.

For at least some species, our study demonstrates that, in addition to demographic information, the ageanalysis of otoliths can provide a unique, albeit indirect, means of reconstructing a history of recruitment events. Typically, such information is obtained from counts of recently settled fish, or by sampling techniques such as light traps (Doherty 1987) or crest nets (Dufour \& Galzin 1993) that capture young fish as they arrive on reefs. These methods are expensive, as they require considerable logistical support and repeated programs of sampling over a long duration in order to produce useful data sets. In contrast, our study has shown that this information may be derived from single collections of fish. This approach will be most successful when the target species are relatively longlived and have low rates of adult mortality. While these conditions will limit the applicability of the technique, the demographic traits revealed by our study show that it is in precisely such situations that the information on recruitment patterns revealed by otoliths may prove to be of the greatest use.

Acknowledgements. Field and laboratory work for this study was funded by a grant from the National Geographic Society (5308-94). Our thanks to Ben Victor for assistance in the field and to Mike Cappo for assistance with laboratory work. We thank the Galápagos National Park Service for granting permission (PC-021-94 SPNG) to work in the Galápagos Archipelago, the staff at the Charles Darwin Research Station and Godfrey Merlen for logistical help. Discussions with Mike Cappo and Peter Doherty and comments from Howard Choat, Mark McCormick, Phil Munday and 2 anonymous reviewers aided in the development of the manuscript. Our thanks also to J. Kritzer (CRC Reef Research Centre, James Cook University) for the software used to analyse growth curves. This is Australian Institute of Marine Science publication number 999. 


\section{LITERATURE CITED}

Allen GR, Robertson DR (1994) Fishes of the eastern tropical Pacific. University of Hawaii Press, Honolulu

Atkinson D (1994) Temperature and organism size-a biological law for ectotherms? Adv Ecol Res 25:1-58

Bertschy KA, Fox MG (1999) The influence of age-specific survivorship on pumpkinseed sunfish life histories. Ecology 80:2299-2313

Choat JH, Axe LM (1996) Growth and longevity in acanthurid fishes: an analysis of otolith increments. Mar Ecol Prog Ser 134:15-26

Choat JH, Axe LM, Lou DC (1996) Growth and longevity in fishes of the family Scaridae. Mar Ecol Prog Ser 145: $33-41$

Craig MT, Pondella DJ, Hafner JC (1999) Analysis of age and growth in two Eastern Pacific groupers (Serranidae: Epinephelinae). Bull Mar Sci 65:807-814

Craig PC, Choat JH, Axe LM, Saucerman S (1997) Population biology and harvest of the coral reef surgeonfish Acanthurus lineatus in American Samoa. Fish Bull 95:680-693

Doherty PJ (1987) Light traps: selective but useful devices for quantifying the distributions and abundances of larval fishes. Bull Mar Sci 41:423-431

Draper NR, Smith H (1966) Applied regression analysis. Wiley \& Sons, New York

Dufour V, Galzin R (1993) Colonization patterns of reef fish larvae to the lagoon at Moorea Island, French Polynesia. Mar Ecol Prog Ser 102:143-152

Ferreira BP, Russ GR (1992) Age, growth and mortality of the inshore coral trout Plectropomus maculatus (Pisces: Serranidae), of the Central Great Barrier Reef, Australia. Aust J Mar Freshw Res 43:1301-1312

Ferreira BP, Russ GR (1994) Age validation and estimation of the growth rate of the coral trout, Plectropomus leopardus (Lacepede 1802), from Lizard Island, Northern Great Barrier Reef. Fish Bull 92:46-57

Ferreira BP, Russ GR (1995) Population structure of the coral trout, Plectropomus leopardus (Lacepede 1802), on fished and unfished reefs off Townsville, Central Great Barrier Reef, Australia. Fish Bull 93:629-642

Fowler AJ (1990) Validation of annual growth increments in the otoliths of a small, tropical coral reef fish. Mar Ecol Prog Ser 64:25-38

Fowler AJ (1995) Annulus formation in coral reef fish - a review. In: Secor DH, Dean JM, Campana SE (eds) Recent developments in fish otolith research. University of South Carolina Press, Columbia, SC, p 45-63

Fox MG, Keast A (1991) Effects of overwinter mortality on reproductive life history characteristics of pumpkinseed (Lepomis gibbosus) populations. Can J Fish Aquat Sci 48: 1791-1799

Francis RICC (1995) The analysis of otolith data - a mathematician's perspective. In: Secor DH Dean JM, Campana SE (eds) Recent developments in fish otolith research. University of South Carolina Press, Columbia, SC, p 81-96

Glynn PW, GM Wellington (1983) Corals and coral reefs of the Galápagos Islands. University of California Press, Berkeley

Grove JS (1984) Influence of the 1982-83 El Niño on the ichthyofauna on the Galápagos Archipelago. Trop Ocean Atmos Newsl 28:18-19

Editorial responsibility: Otto Kinne (Editor),

Oldendorf/Luhe, Germany
Grove JS, Gerzon D, Saa D, M Strang (1986) Distribución y ecología de la familia Pomacentridae (Pices) en las Islas Galápagos. Rev Biol Trop 34:127-140

Houvenaghel GT (1984) The oceanographic setting of the Galápagos Islands. In: Perry R (ed) Key environments: Galápagos. Pergamon Press, Oxford, p 43-54

Hutchings JA (1997) Life history responses to environmental variability in early life. In: Chambers RC, Trippel EA (eds) Early life history and recruitment in fish populations. Chapman \& Hall, London, p 139-168

Kimura DK (1980) Likelihood methods for the von Bertalanffy growth curve. Fish Bull 77:765-776

Meekan MG, Wellington GM, Axe L(1999) El Niño-Southern Oscillation events produce checks in the otoliths of coral reef fishes in the Galápagos Archipelago. Bull Mar Sci 64: 383-390

Merlen G (1988) Two new butterfly fish records from Wenman Island. Not Galápagos 46:8-9

Munro JL (1996) The scope of tropical reef fisheries and their management. In: Polunin NVC, Roberts CM (eds) Reef fisheries. Chapman \& Hall, London, p 1-14

Munro JL, Williams DM (1985) Assessment and management of coral reef fisheries: biological, environmental and sociological aspects. Proc 5th Int Coral Reef Congr 4: 545-581

Myers RA (1991) Recruitment variability and the range of three fish species. NAFO (Northwest AtL Fish Organ) Sci Counc Stud 16:21-24

Newman SJ, Williams D McB, Russ GR (1996a) Variability in the population structure of Lutjanus adetii (Castelnau 1873) and L. quinquelineatus (Bloch 1790) among reefs in the central Great Barrier Reef, Australia. Fish Bull 94: 313-329

Newman SJ, Williams DMcB, Russ GR (1996b) Age validation, growth and mortality rates of the tropical snappers (Pisces: Lutjanidae) Lutjanus adetii (Castelnau 1873) and L. quinquelineatus (Bloch 1790) from the central Great Barrier Reef, Australia. Mar Freshw Res 47:575-584

Pauly D (1984) Fish population dynamics in tropical waters: a manual for use with programmable calculators. ICLARM, Manila

Reznick DN, Bryga H, Endler JA (1990) Experimentallyinduced life history evolution in a natural population. Nature 346:357-359

Russ GR (1991) Coral reef fisheries: effects and yields. In: Sale PF (ed) The ecology of fishes on coral reefs. Academic Press, San Diego, p 601-635

Russ GR, Lou DC, Ferreira BP (1996) Temporal tracking of a strong cohort in the population of a coral reef fish, the coral trout, Plectropomus leopardus (Serranidae: Epinephelinae), in the central Great Barrier Reef, Australia. Can J Fish Aquat Sci 53:2745-2751

Sale PF (1980) The ecology of fishes on coral reefs. Oceanogr Mar Biol Annu Rev 18:367-421

Schnute J (1981) A versatile growth model with statistically stable parameters. Can J Fish Aquat Sci 38:1128-1140

Wellington GM, Dunbar RB (1995) Stable isotopic signature of El Niño-Southern Oscillation events in eastern tropical Pacific reef corals. Coral Reefs 14:5-25

Zar JH (1984) Biostatistical analysis, 2nd edn. Prentice Hall, Englewood Cliffs, NJ

Submitted: January 26, 2000; Accepted: August 1, 2000

Proofs received from author(s): February 12, 2001 